\section{Occurrence of the Terrestrial Alga, Fritschiella tuberosa, lyengar, in Africa}

THE terrestrial Chætophoraceous alga, Fritschiella tuberosa, which was first discovered ${ }^{1}$ by Prof. M. O. P. Iyengar in India from soil in drying rain-pools in Madras and Mysore, and later recorded from Fyzabad ${ }^{2}$ and the Benares district ${ }^{3}$, has now been found at Khartoum, in the Anglo-Egyptian Sudan. It occurs there during August, September and October in drying silt on the banks of the Blue Nile as the river recedes after the summer floods. It has been found in this situation for three years in succession with the alga Protosiphon botryoides (Kutz.), Klebs., var. deserti, Nayal, and grows in such profusion that the bare silt assumes a distinctly green coloration.

The Khartoum plants, though in general agreeing well with the descriptions of Iyengar and Singh, differ, however, in the poor development of the secondary projecting system. Observations in the field and under laboratory conditions suggest that this is due to the very dry atmospheric conditions and high temperatures occurring in Khartoum.

It is proposed to publish elsewhere a more detailed account of observations relating to the occurrence of Fritschiella in Khartoum.

\section{A. J. Ввоок}

Department of Botany,

Gordon Memorial College, University College of Khartoum,

Anglo-Egyptian Sudan. Nov. 26.

${ }^{1}$ Iyengar, M. O. P., New Phytol., 31 (1932).

'Randhawa, M. S., Arch. Protist., 82 (1939).

singh, R. H., New Phytol., 40 (1941).

\section{Possible Protozoan Remains in Permian Salt}

Some years ago, Dr. G. M. Lees asked me to examine some 4-in. cores of Permian rock salt from the Eskdale bore hole, N. Yorkshire, of which the stratigraphy has been described ${ }^{1}$. The specimens were mainly from the Middle Saline Group, 3,900-4,200 ft. The cores had been kept in sealed glass jars and were in good condition for examination. The salt of this zone is mainly stained red or pink by disseminated fine hæmatite, and these iron-rich salts contain the bodies here mentioned, of which a fuller account will be published elsewhere.

On breaking the cores to obtain fresh uncontaminated material, washing and afterwards immersing small fragments in distilled water and observing the process of solution under a $\times 50$ binocular, a number of interesting features may be observed.

Occluded gas begins to be released immediately in minute bubbles and, as solution progresses, red filamentous material may be released in longish masses bound together sometimes by a mesh of fine siliceous threads embedded in a mucilaginous mass. Individual masses or colonies may be up to 2

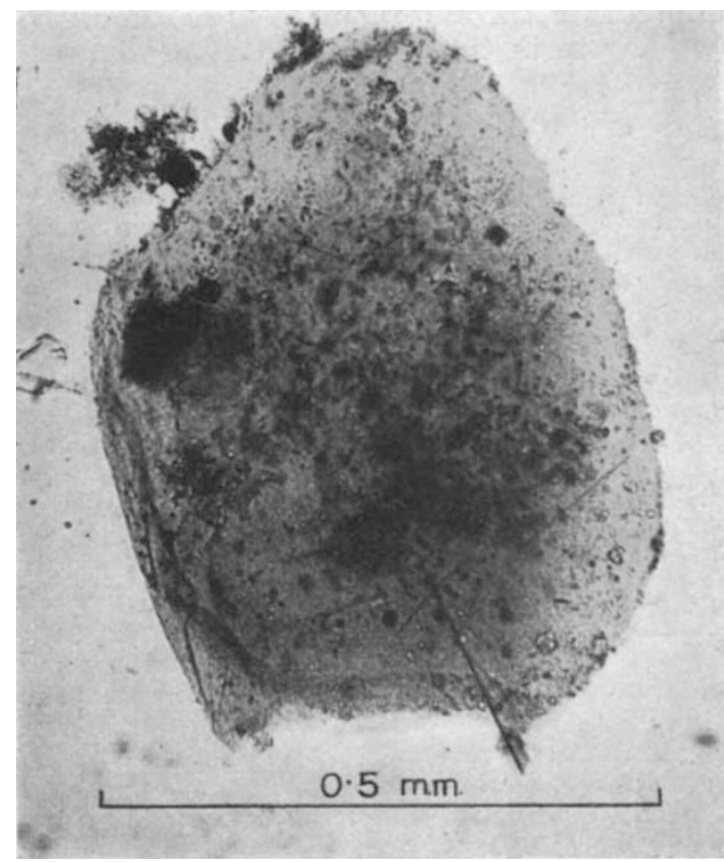

Fig. 1

or $3 \mathrm{~mm}$. long, and in them are occasionally found reddish globular or lobed cyst-like sacs which can bo freed from the matrix (Fig. 1). These may be transparent when wet; but, after washing with distilled water and dehydrating with acetone, they are seen to be collapsed membranous sacs. These 'cysts' $(0.2 \mathrm{~mm} .-1 \mathrm{~mm}$. in diameter) may be clear, honeyyellow or red-brown with areas of deeper colouring, but no definite structural detail is visible under ordinary light and no stains have yet been found to react with them. A few circular areas have been noted but are inconclusive as vacuoles. Some specimens exhibit a few straight spicules within or protruding from the periphery. The sacs are permeable.

Distinct from the above are pieces of broken membrane composed of a yellowish to transparent mucilaginous matrix in which is embedded a dense mesh of fine silica (?) threads up to several millimetres long. The threads of filaments or spicules may be straight, eurved or closely coiled, usually

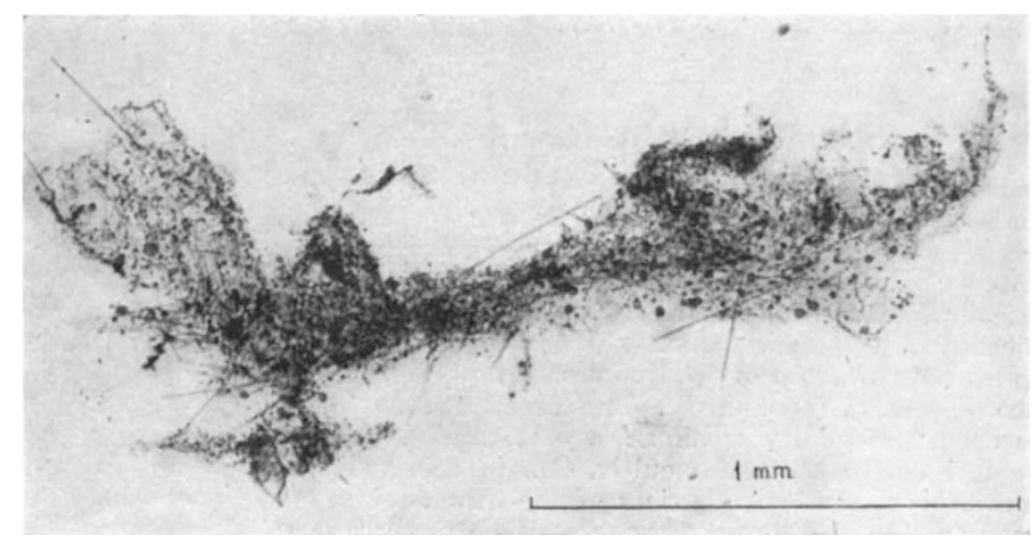

Fig. 2 